\title{
Deep Learning Performance on Medical Image, Data and Signals
}

\author{
A Review of Recent Studies \\ (D) Pakize ERDOGMUS ${ }^{1}$ \\ ${ }^{1}$ Duzce University \\ Computer Engineering \\ Duzce \\ pakizeerdogmus@duzce.edu.tr
}

Received: 18/03/2019; Revision; 19/03/2019 Accepted; 28/03/2019 Published online; 25/04/2019

\begin{abstract}
In this study, the recent medical studies with deep learning between 2009-2019 have been researched for observing the performance of deep learning on medical images, data and signal. Recent studies attained from Web of Science have been evaluated and selected according to the citation numbers. Studies have been listed as a table, according to the publication year, deep network structure, database used training and testing, evaluation metric and results. The studies have also been classified into the organs and the types of important diagnosis. The results have shown that the deep learning network structures, applied on fundus images, have attained nearly \%99 percent accuracy. Although most of the studies between the range, made by Radiology and Nuclear Medicine Imaging, the accuracy of the results are $80-90 \%$ range. The current studies especially focus on automatic detection or classification of the tumor as benign or malign. Studies are mostly on medical CT, ultrasound, radiography and MRI images. This results show that computer aided medical diagnosis systems will be used in a very near future with fully performance.
\end{abstract}

Keywords: medical data, deep learning, convolutional neural networks

\section{Tıbbı Görüntü, Veri ve Sinyaller Üzerinde Derin Öğrenme Performansları}

\section{$\ddot{\mathbf{O} z}$}

Bu çalışmada, 2009-2019 yılları arasında Tıpta derin öğrenme ile ilgili yapılmış çalışmalar, derin öğrenmenin Tıbbı görüntü, veri ve sinyaller üzerine başarısını gözlemlemek için araştırılmıştır. Web of Science'tan elde edilen çalışmalar değerlendirilmiş ve atıf sayısına göre seçilmiş̧lerdir. Çalışmalar yayın yılı, derin ağ yapısı, kullanılan veritabanı ve değerlendirme kriterine göre tablo haline getirilmiştir. Çalışmalar organlara göre ve tanılara göre de sınıflandırılmıştır. Sonuçlar retinal fundus görüntüleri uygulanan derin öğrenme ağ yapılarının doğruluklarının \%99'lara ulaştığını göstemektedir. Bu aralıktaki çalışmaların çoğu radyoloji ve nükleer tıp alanında yapılmış olsa de sonuçlar henüz \%80-90 aralığında görülmektedir. Yapılan çalışmalar özellikle tümörlerin otomatik tesbiti veya tümörlerin iyi veya kötü huylu olarak sınıflandırılması üzerinedir. Çalışmalar çoğunlukla tıbbı tomografi, ultrases, radyografi ve manyetik resonans görüntüler üzerinedir. Bu sonuçlar bilgisayar destekli teşhis sistemlerinin çok yakın bir gelecekte tam performans ile kullanılacağını göstermektedir.

Anahtar kelimeler: Tıbbi veri, derin öğrenme, konvolusyonel sinirsel ağlar

\section{Introduction}

Learning can be thought of as a "Two-step process involving the reception and processing of information. In the reception step, external information and internal information become available and a learner, who select the material he/she will process and ignore the rest. The processing step involves 
simple memorization or inductive or deductive reasoning, reflection or action, and introspection or interaction with others." The outcome is that the material is either "learned" or not learned [1].

Machine learning is also defined as two-step process, similar to the educational definition of learning. In the first step, external data is shown to the machine. But different from the human, machine can't select the features which are useful for learning. So feature extraction is applied, before the learning process. For example, a student, listening her/his teacher in order to learn a topic, takes notes for increasing the percentage of learning. But, machine learning methods process the extracted features of the data. So machine learning methods require the help of human.

Representation learning allows a machine to be fed with raw data and to automatically discover the representations needed for detection or classification like human. Deep-learning methods are representation-learning methods. Multiple levels of layers, extract feature and abstract data. As a result, very complex functions can be learned [2]. Since deep learning methods requires a very little effort for learning process, there is an increasing trend using deep learning in medical studies in recent years.

This review focuses especially the deep learning methods in Medical Studies. So the other, artificial intelligence methods used in the medical studies are excluded. But researchers can reach a very detailed manuscript, published by Kononenko [3]. Studies between 2009-2019 have been researched. Researches have been done with the "Medical deep learning" keywords in Web of Science [4]. While the total 1923 studies are from 1991 to 2019, the number of the studies between 2009-25.03.2019 is 1735. The studies are categorized into different criterias. 1032 articles and 593 conference papers and 103 reviews have been published between this range. Average citation per item has been found as 7.55.

Most of the studies with deep learning are related to ophthalmology [5-9]. The studies on deep learning have been published by the departments of radiolaogy, nuclear medicine, optics, surgery and obstetrics gynecology, respectively. The studies are classified into detection [9,10], recognition[11], classification [12], and segmentation [13].

The detection studies are mostly on automatic detection via deep learning. Detection of diabetic retinopaty [5], chest patology detection [30], microcalcification detection [47], pulmonary nodule detection [48,49], lesion detection [50], lung nodule detection [51], pulmonary cancer detection [52], detection of thyroid nodules [53], polyp detection [54] are some of the detection studies. Some of the studies on recognition are body parts recognition [55], automatic recognition of severity level for diagnosis of diabetic retinopathy[11], different cardiac diases pattern recognition[56] and teeth recognition[57]. Classification studies consist ECG signal classification[31], lung pattern classification[25], Mammographic tumor classification[35]. Most of the recent studies focus on segmentation, such as brain tumor segmentation [27],pancreas segmentation[33] and left ventricle segmentation[39].

The network architecture, used in these studies, are generally, $\mathrm{CNN}$ (Convolutional Neural Network)[23-25], RNN(Recurrent Neural Network), AE( Auto Encoders)[40] and DBN( Deep Blief Network)[39].

The rest of this review is detailed as followed. In Section 2, deep learning is introduced. In Section 3, deep learning in medical studies is overviewed. And lastly, the results of the articles reviewed here have been interpreted with a general perspective.

\section{Deep Learning}

Deep learning is a general definition of a class of algorithms which optimize the neural network to be able to work with unstructured data [14]. Neural learning networks have been based on synapses of a general type described by Hebb and Eccles [15-17]. The classical neural learning network is combination of the perceptron, which composed of inputs, weights, activation function and output. Networks are designed as multi-layers. Each layer consists of a number of perceptrons. Neural network, used for classification, requires processed data, to be able to perform well. In visual processing, for example, feature extraction should previously have been done [17]. Deep-network architecture is a multilayer neural network to be able to accept unstructured raw data, such as images, voice, videos and text. In the CNN architecture, Convolutional Layers, Rectified Linear Unit (RELU), Pooling Layers and Fully Connected Layers are used for creating a multi-layer deep convolutional 
neural network. Convolution layer, compute the output of neurons that are connected to the input. RELU is the activation function. Pooling layers, progressively reduce the spatial size of the representation to reduce the computation. The Fully connected layers calculate the output label percentage [18]. Convolutional Neural netwok (CNN), Unsupervised Pretrained Networks (UPN), Recurrent Neural Networks (RNN) and Recursive Neural Networks are deep neural network architectures. A sample Convolutional Neural Network architecture has been shown in Figure 1.

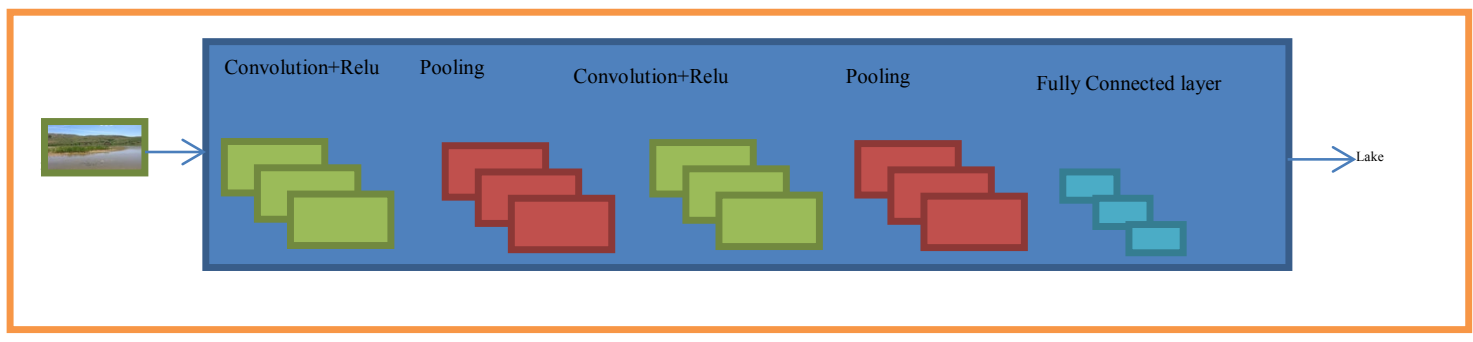

Figure 1 Convolutional Neural Network Layers

In recent years, a lot of pre-trained CNNs are available for researchers to implement their studies. These networks have been trained with millions of images, such as ImageNet[19]. The most popular ones are Mathworks, AlexNET, GoogLeNet, VGG-Net and ResNets[20].

The learning process of network has two main steps as training and testing. In training step, inputs are fed with data and output labels are shown. The training is to adapt the network weights to provide the desired output for a given input. Each layer has been trained for a number of sweeps through the training set, which is called "epochs" [21]. The performance of the learning is tested with test data. Specifity, Sensitivity, accuracy and AUC(Area of ROC Curve) are most used performance evaluation metrics. Specifity, Sensitivity and Accuracy formulations have been given in Equation 1,2 and 3 respectively. AUC is more preferred than accuracy [22].

$$
\begin{aligned}
& \text { Specifity }=\frac{T N}{T N+F P} \\
& \text { Sensitivity }=\frac{T P}{T P+F N} \\
& \text { Accuracy }=\frac{T P+T N}{T P+T N+F P+F N}
\end{aligned}
$$

\section{TP: Positives correctly classified}

TN: Negatives correctly classified

FP: Negatives incorrectly classified

FN: Positives incorrectly classified

AUC was proposed for evaluation of machine learning performance in recent years, even if it was popular for medical diagnosis studies[22].

\section{Deep Learning in Medical Studies}

Deep learning is a subclass of machine learning methods that are increasing their accuracy in a lot of different areas, including computer vision, speech recognition, natural language processing[58]. The articles found with medical deep learning keywords at WebofScience have been evaluated in this study. In Medical deep learning studies between 2009-2019 have been classified as given in figure 2. 


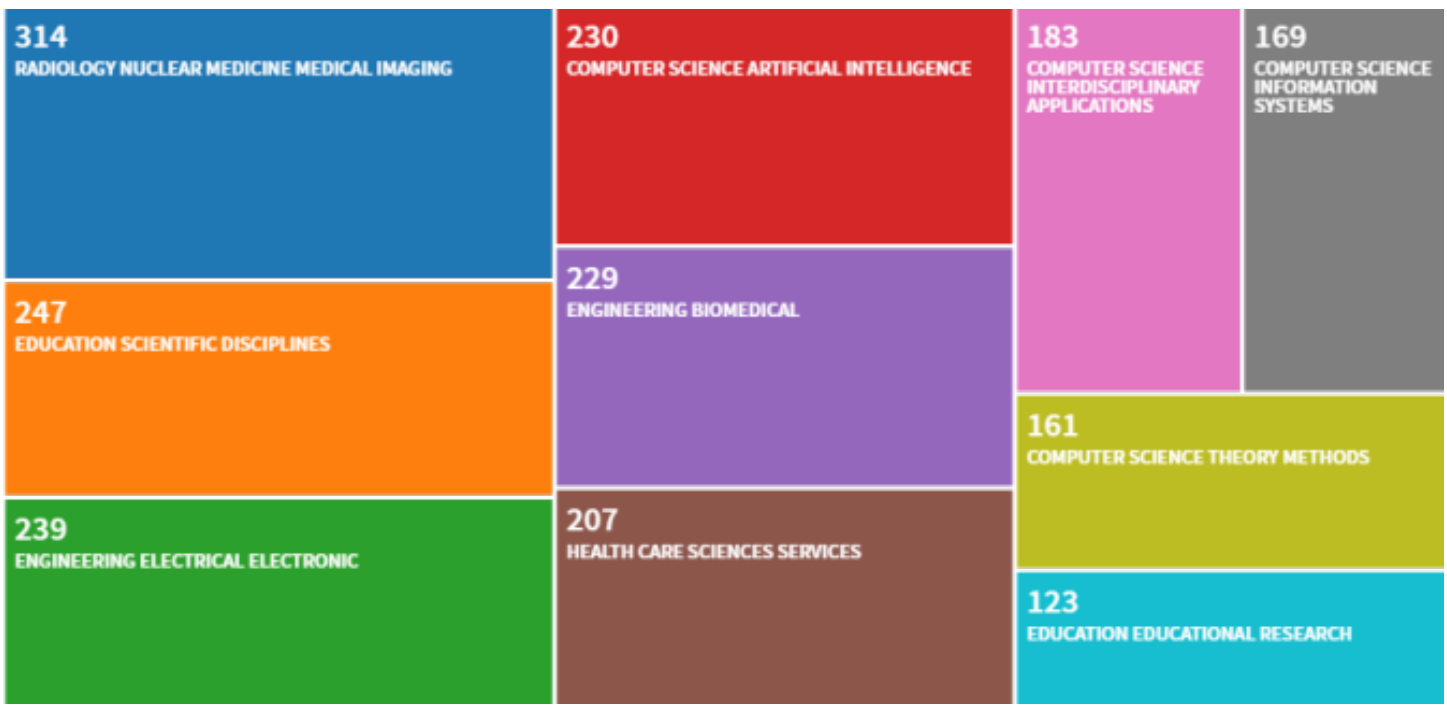

Figure 2 The Categories of Medical Deep Learning Studies[4]

As it has been seen in the Figure 2, the higher percentage of the studies has been done in Radiology and Nuclear Medicine Medical Imaging. The number of the studies published in each year between the ranges has been shown in Figure 3.

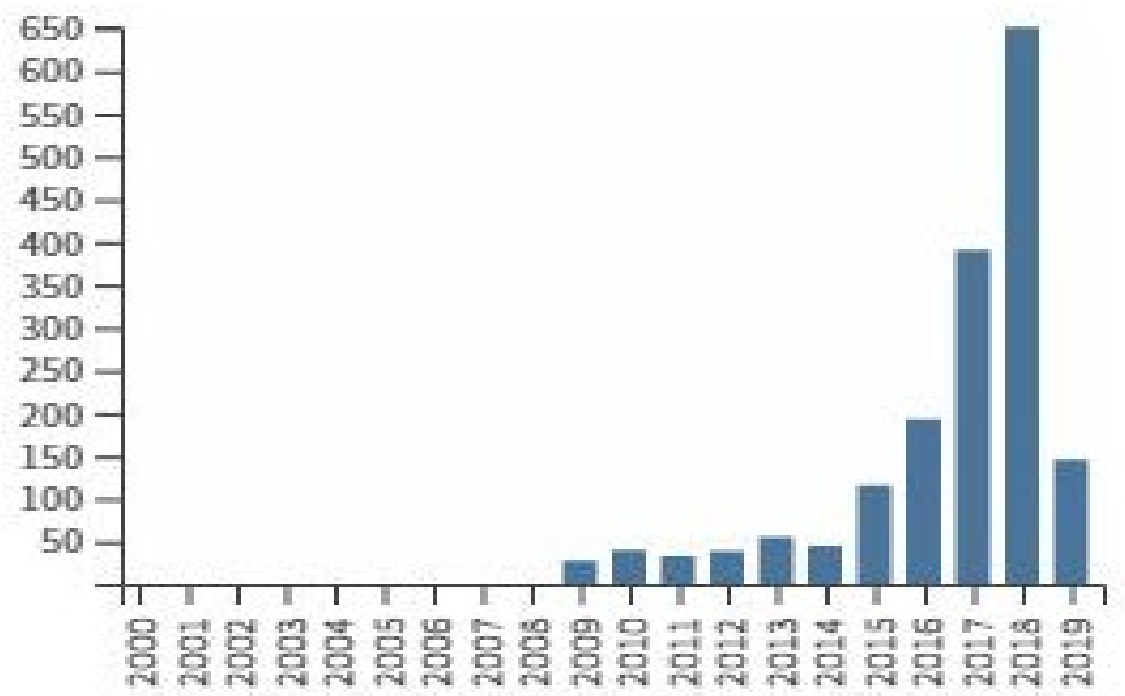

Figure 3 Total Publications by Year[4]

As seen in the Figure 3, the studies on deep learning have boomed in last year. According to this graphic, it is certain that, this trend will also increase in 2019. The studies mostly are carried out last four years. The most cited articles have been given in the Table 1.

Table 1 The Most Cited Medical Deep Learning Studies

\begin{tabular}{|l|l|l|l|l|}
\hline No & $\begin{array}{l}\text { Pub. } \\
\text { Year, } \\
\text { Cited by }\end{array}$ & Topic & $\begin{array}{l}\text { Network and } \\
\text { Dataset }\end{array}$ & Success \\
\hline$[5]$ & $\begin{array}{l}12-2016, \\
429\end{array}$ & $\begin{array}{l}\text { Detection of diabetic } \\
\text { retinopathy in retinal } \\
\text { fundus images }\end{array}$ & $\begin{array}{l}\text { CNN } \\
\text { EyePACS-1 } \\
\text { Mesidor-2 }\end{array}$ & $\begin{array}{l}\text { Sensitivity:0.975 } \\
\text { Sensitivity:0.961 }\end{array}$ \\
\hline$[24]$ & $\begin{array}{l}2-2017, \\
249\end{array}$ & $\begin{array}{l}\text { Brain lesion } \\
\text { segmentation }\end{array}$ & $\begin{array}{l}\text { 3D CNN } \\
\text { BRATS 2015 } \\
\text { ISLES 2015 }\end{array}$ & $\begin{array}{l}\text { Sensitivity:0.885 } \\
\text { Sensitivity: } 0.876\end{array}$ \\
\hline
\end{tabular}


Table 1 The Most Cited Medical Deep Learning Studies (Continue)

\begin{tabular}{|c|c|c|c|c|}
\hline No & $\begin{array}{l}\text { Pub. } \\
\text { Year, } \\
\text { Cited by }\end{array}$ & Topic & $\begin{array}{l}\text { Network and } \\
\text { Dataset }\end{array}$ & Success \\
\hline$[25]$ & $\begin{array}{l}5-2016 \\
145\end{array}$ & $\begin{array}{l}\text { Lung pattern } \\
\text { classification }\end{array}$ & $\begin{array}{l}\text { CNN } 14696 \text { image } \\
\text {,120 CT scans }\end{array}$ & Accuracy:0.855 \\
\hline$[26]$ & 2013,130 & $\begin{array}{l}\text { Knee cartilage } \\
\text { segmentation }\end{array}$ & $\begin{array}{l}\text { CNN } \\
114 \mathrm{MRI}\end{array}$ & Specifity:0.9997 \\
\hline$[27]$ & $\begin{array}{l}5-2016 \\
250\end{array}$ & $\begin{array}{l}\text { Brain Tumor } \\
\text { Segmentation }\end{array}$ & $\begin{array}{l}\text { CNN } \\
\text { BRATS } 2013 \\
\text { BRATS } 2015\end{array}$ & $\begin{array}{l}\text { Sensitivity:0.89 } \\
\text { Sensitivity: } 0.78\end{array}$ \\
\hline [28] & $\begin{array}{l}01-2017, \\
261\end{array}$ & $\begin{array}{l}\text { Brain Tumor } \\
\text { Segmentation }\end{array}$ & $\begin{array}{l}\text { DNN } \\
\text { BRATS2013 }\end{array}$ & Specifity:0.88 \\
\hline [29] & $\begin{array}{l}10-2016, \\
155\end{array}$ & $\begin{array}{l}\text { Volumetric Medical } \\
\text { Image } \\
\text { Segmentation }\end{array}$ & $\begin{array}{l}\text { Fully CNN } \\
\text { PROMISE } 2012\end{array}$ & Dice:0.869 \\
\hline$[30]$ & 2015,62 & Pathology detection & $\begin{array}{l}\text { CNN } \\
\text { Chest X-Ray dataset }\end{array}$ & AUC:0.87-0.94 \\
\hline$[31]$ & 2016,77 & ECG classification & $\begin{array}{l}\text { DNN } \\
\text { MIT-BIH } \\
\text { Arrhythmia } \\
\text { Database }\end{array}$ & AUC:0.996 \\
\hline$[32]$ & 2015,337 & $\begin{array}{l}\text { DNA sequence } \\
\text { prediction }\end{array}$ & $\begin{array}{l}\text { Deep Network } \\
\text { - }\end{array}$ & $\begin{array}{l}\text { DeepFind } \\
\text { AUC: } 0.73\end{array}$ \\
\hline [33] & 2015,71 & $\begin{array}{l}\text { Pancreas } \\
\text { Segmentation }\end{array}$ & $\begin{array}{l}\text { Deep CNN } \\
\text { ConvNet Medical } \\
\text { Image Dataset }\end{array}$ & $\begin{array}{l}\text { Dice: } 0.836 \\
\text { training } \\
0.718 \text { test }\end{array}$ \\
\hline$[34]$ & $\begin{array}{l}9-2015 \\
67\end{array}$ & $\begin{array}{l}\text { Standard plane } \\
\text { localization in fetal } \\
\text { ultrasound }\end{array}$ & $\begin{array}{l}\text { CNN } \\
1991 \text { positive samples } \\
3160 \text { negative }\end{array}$ & Accuracy:0.904 \\
\hline [35] & $\begin{array}{l}9-2016 \\
49\end{array}$ & $\begin{array}{l}\text { Mammographic } \\
\text { tumor classification }\end{array}$ & $\begin{array}{l}\text { CNN } \\
219 \text { breast lesions } \\
\text { ( } 607 \text { image) }\end{array}$ & AUC:0.81 \\
\hline$[7]$ & $\begin{array}{l}6-2017 \\
44\end{array}$ & $\begin{array}{l}\text { Identification of } \\
\text { diabetic retinopathy }\end{array}$ & $\begin{array}{l}\text { DR Deep learning } \\
\text { tool } \\
\text { Messidor } 2 \\
\text { E-Optha }\end{array}$ & AUC:0.97 \\
\hline [37] & 2016,37 & $\begin{array}{l}\text { Retinal vessel } \\
\text { segmentation }\end{array}$ & $\begin{array}{l}\text { Fully-connected } \\
\text { conditional random } \\
\text { fields } \\
\text { DRIVE } \\
\text { STARE }\end{array}$ & $\begin{array}{l}\text { Accuracy:0.9470 } \\
\text { Accuracy:0.9545 }\end{array}$ \\
\hline$[38]$ & $\begin{array}{l}3-2018 \\
38\end{array}$ & $\begin{array}{l}\text { Prediction of } \\
\text { cardiovascular risk }\end{array}$ & $\begin{array}{l}\text { Soft-attention } \\
\text { UK Biobank clinical } \\
\text { validation set } \\
\text { EyePACS-2K clinical } \\
\text { validation set }\end{array}$ & AUC:0.97 \\
\hline [39] & $\begin{array}{l}3-2012 \\
51\end{array}$ & $\begin{array}{l}\text { Left ventricle } \\
\text { segmentation }\end{array}$ & $\begin{array}{l}\text { Deep Blief Network } \\
400 \text { annoted image }\end{array}$ & AUC:0.95 \\
\hline$[40]$ & $\begin{array}{l}12-2018, \\
5\end{array}$ & $\begin{array}{ll}\text { ECG } & \text { signal } \\
\text { compression }\end{array}$ & $\begin{array}{l}\text { MIT-BIH } \\
\text { Deep convolutional } \\
\text { autoencoder }\end{array}$ & $\begin{array}{l}\text { Compression } \\
\text { ratio: } 32.25 \%\end{array}$ \\
\hline
\end{tabular}

This table shows that the most cited and successful studies are on retinal fundus images. Medical image segmentation studies are lively topic for deep learning, since the accuracy is nearly $80-90 \%$. And the most cited reviews have been given in Table 2 . 
Table 2 The Most Cited Reviews

\begin{tabular}{|c|c|c|c|}
\hline Ref. & Publication Year & Cited by & Topic \\
\hline [41] & $5-2016$ & 443 & CNN in medical image analysis \\
\hline [42] & $12-2017$ & 340 & Deep learning in medical image analysis \\
\hline [43] & $5-2016$ & 256 & CNN in medical image analysis \\
\hline [44] & $5-2016$ & 236 & Deep learning in medical imaging \\
\hline [45] & 2017 & 158 & Deep learning in medical image analysis \\
\hline [46] & 2016 & 28 & $\begin{array}{l}\text { MRI-based brain tumor image segmentation } \\
\text { using deep learning methods }\end{array}$ \\
\hline
\end{tabular}

In order to evaluate the studies, brain, cardiac, pulmonary, hepatic and fundus keywords have been researched in the studies. The number of the studies for each organ has been given in Table 3 .

Table 3 The Medical Deep Learning Studies Classification According to Organs

\begin{tabular}{|c|c|c|c|}
\hline Organ & $\begin{array}{l}\text { Most } \\
\text { Cited } \\
\text { Refs }\end{array}$ & Topics & $\begin{array}{l}\text { Imaging Techniques } \\
\text { + Network Architecture }\end{array}$ \\
\hline \multirow{6}{*}{$\begin{array}{l}\text { Brain } \\
(167)\end{array}$} & 249 & Brain lesion segmentation[24 ] & Multi Modal Brain MRI+CNN \\
\hline & 30 & Brain Segmentation [59] & $\begin{array}{l}\text { Brain MRI+Voxelwise residual } \\
\text { network }\end{array}$ \\
\hline & 14 & Brain region segmentation[60] & MRI+Ultrasound+Hough CNN \\
\hline & 5 & Image Classification[61] & CT+ DNN(Deep Neural Network) \\
\hline & 12 & Prediction of MGMT Methylation Status[62] & MRI+ResNET \\
\hline & 2 & Brain Hemorrhage [63] & $\mathrm{CT}+\mathrm{CNN}$ \\
\hline \multirow{3}{*}{$\begin{array}{r}\text { Cardiac } \\
(47)\end{array}$} & 50 & Segmentation of left ventricle[64] & MRI+Level Set+DBN \\
\hline & 2 & Ventricle segmentation[65] & $\mathrm{MRI}+\mathrm{CNN}$ \\
\hline & 0 & Assessment of myocardial infarction[66] & $\mathrm{MR}+\mathrm{CNN}$ \\
\hline \multirow{4}{*}{$\begin{array}{c}\text { Pulmonary } \\
\text { (53) }\end{array}$} & 97 & Pulmonary nodule diagnosis[67] & $\mathrm{CT}+\mathrm{CNN}$ \\
\hline & 37 & Automatic detection of pulmonary nodules[68] & CT \\
\hline & 24 & $\begin{array}{llll}\text { Detection of } & \text { abnormalities } & \text { on } & \text { chest } \\
\text { radiograph[69] } & & & \end{array}$ & Radiograph $+\mathrm{CNN}$ \\
\hline & 21 & $\begin{array}{lll}\text { Automatic scoring of multiple } & \text { semantic } \\
\text { attributes on } & \text { pulmonary nodules[70] } & \\
\end{array}$ & CT \\
\hline \multirow{2}{*}{$\begin{array}{l}\text { Hepatic } \\
\text { Liver } \\
\text { (8) }\end{array}$} & 1 & Classification of mice hepatic granuloma[71] & Microscopic Images + CNN \\
\hline & 1 & Liver lesion classification[72] & $\mathrm{CNN}$ \\
\hline \multirow{4}{*}{$\begin{array}{r}\text { Retinal } \\
(58)\end{array}$} & 429 & $\begin{array}{l}\text { Detection of diabetic retinopathy in retinal } \\
\text { fundus images[5] }\end{array}$ & Retinal fundus images $+\mathrm{CNN}$ \\
\hline & 63 & $\begin{array}{llll}\begin{array}{l}\text { Deep learning } \\
\text { retinopathy[36] }\end{array} & \text { system } & \text { for } & \text { diabetic } \\
\end{array}$ & DR Deep Learning Tool \\
\hline & 37 & Retinal vessel segmentation[37] & $\begin{array}{l}\text { Fully-connected } \\
\text { random fields }\end{array}$ \\
\hline & 1 & Detecting diabetic retinopathy[23] & Retinal fundus images $+\mathrm{CNN}$ \\
\hline
\end{tabular}


According to the results, brain image segmentation is the mostly studied topic for tumor classification. 73 of the 167 studies are on segmentation. Studies have not been focused exactly on specific disease. But there are studies focused on epileptic seizure[73], Alzheimer[74] migraine [75] and Parkinson. The studies on cardiac are especially on ventricle segmentation $[64,65]$ and tracking [76]. The studies carried out on lung are the lung nodule detection, classification and cancer detection on CT imaging and radiograph. The studies focus on diagnosis of some disease with deep learning. Table 4 shows some diagnosis keywords and the number of the studies carried out for this diagnosis on medical images. The number of the studies for each keyword given in Table 4, is not exactly different from each other. Some of the studies have been counted on more then one diagnosis item. The title of the studies combine the three subtitles given in the tables (Table 1,3,4). For example "Brain tumor segmentation" combines three classification categories given in the tables.

Table 4 Some Important Diagnosis Keywords and The Studies Carried Out For These Diagnoses with Deep Learning

\begin{tabular}{|l|l|}
\hline Diagnosis & The number of studies with Deep Learning \\
\hline Hemorrage [10] & 13 \\
\hline Nodule[77] & 63 \\
\hline Polyp[78] & 20 \\
\hline Tumor[79] & 115 \\
\hline Cancer[80] & 244 \\
\hline Calcification[81] & 8 \\
\hline
\end{tabular}

\section{Results}

Even if convolutional neural networks have been proposed nearly for 25 years, due to the computers power, they have been popular for last decade. So in this study, the articles published between 20092019 have been researched. Recent studies on deep learning have shown promising results on medical data. So in the very near feature, the medical diagnosis support systems using deep learning will increase. The most successful studies are on retinal fundus images. The success of the recent studies on retinal fundus images is nearly $100 \%$. The second success is belong to ECG signal classification studies. Tumor segmentation studies are between $80-90 \%$ successes. So, medical image segmentation will continue to be studied. Researchers focus on the detection of hemorrage, inflammation, nodule, polyp, calsification, cancer or tumor. The succes of those diagnosis will increase with the increasing rate of accuracy of segmentation on related medical images.

\section{References}

[1] Felder, Richard M., and Linda K. Silverman. "Learning and teaching styles in engineering education." Engineering education78.7 (1988): 674-681.

[2] LeCun, Yann, Yoshua Bengio, and Geoffrey Hinton. "Deep learning." nature 521.7553 (2015): 436.

[3] Kononenko, Igor. "Machine learning for medical diagnosis: history, state of the art and perspective." Artificial Intelligence in medicine 23.1 (2001): 89-109.

[4] https://www.webofknowledge.com, Last acces date: 25.03.2019. 
[5] Gulshan, Varun, et al. "Development and validation of a deep learning algorithm for detection of diabetic retinopathy in retinal fundus photographs." Jama 316.22 (2016): 2402-2410.

[6] Abràmoff, Michael David, et al. "Improved automated detection of diabetic retinopathy on a publicly available dataset through integration of deep learning." Investigative ophthalmology \& visual science 57.13 (2016): 5200-5206.

[7] Gargeya, Rishab, and Theodore Leng. "Automated identification of diabetic retinopathy using deep learning." Ophthalmology124.7 (2017): 962-969.

[8] Quellec, Gwenolé, et al. "Deep image mining for diabetic retinopathy screening." Medical image analysis 39 (2017): 178-193.

[9] Schlegl, Thomas, et al. "Fully automated detection and quantification of macular fluid in OCT using deep learning." Ophthalmology 125.4 (2018): 549-558.

[10] Van Grinsven, Mark JJP, et al. "Fast convolutional neural network training using selective data sampling: application to hemorrhage detection in color fundus images." IEEE transactions on medical imaging 35.5 (2016): 1273-1284.

[11] Abbas, Qaisar, et al. "Automatic recognition of severity level for diagnosis of diabetic retinopathy using deep visual features." Medical \& biological engineering \& computing 55.11 (2017): 1959-1974.

[12] Dutta, Suvajit, et al. "Classification of diabetic retinopathy images by using deep learning models." International Journal of Grid and Distributed Computing 11.1 (2018): 89-106.

[13] Zhang, Defeng, et al. "Automatic localization and segmentation of optical disk based on faster R-CNN and level set in fundus image." Medical Imaging 2018: Image Processing. Vol. 10574. International Society for Optics and Photonics, 2018.

[14] Vijay Kotu, Bala Deshpande, Chapter 10 - Deep Learning, Editor(s): Vijay Kotu, Bala Deshpande, Data Science (Second Edition), Morgan Kaufmann, 2019, Pages 307-342, ISBN 9780128147610 .

[15] Hebb, D. 0. (1949) The Organization of Behavior (Wiley, New York).

[16] Eccles, J. G. (1953) The Neurophysiological Basis of Mind (Clarendon, Oxford).

[17] Hopfield, John J. "Neural networks and physical systems with emergent collective computational abilities." Proceedings of the national academy of sciences 79.8 (1982): 2554-2558.

[18] Sünderhauf, Niko, et al. "On the performance of convnet features for place recognition." arXiv preprint arXiv:1501.04158 (2015).

[19] https://www.image.net/, Last acces date: 14.03.2019. 
[20] Huang, Gao, et al. "Densely connected convolutional networks." Proceedings of the IEEE conference on computer vision and pattern recognition. 2017.

[21] Hinton, Geoffrey E., Simon Osindero, and Yee-Whye Teh. "A fast learning algorithm for deep belief nets." Neural computation 18.7 (2006): 1527-1554.

[22] Huang, Jin, and Charles X. Ling. "Using AUC and accuracy in evaluating learning algorithms." IEEE Transactions on knowledge and Data Engineering17.3 (2005): 299-310

[23] Raman, Rajiv, et al. "Fundus photograph-based deep learning algorithms in detecting diabetic retinopathy." Eye (2018): 1.

[24] Kamnitsas, Konstantinos, et al. "Efficient multi-scale 3D CNN with fully connected CRF for accurate brain lesion segmentation." Medical image analysis 36 (2017): 61-78.

[25] Anthimopoulos, Marios, et al. "Lung pattern classification for interstitial lung diseases using a deep convolutional neural network." IEEE transactions on medical imaging 35.5 (2016): 1207-1216.

[26] Prasoon, Adhish, et al. "Deep feature learning for knee cartilage segmentation using a triplanar convolutional neural network." International conference on medical image computing and computer-assisted intervention. Springer, Berlin, Heidelberg, 2013.

[27] S. Pereira, A. Pinto, V. Alves and C. A. Silva, "Brain Tumor Segmentation Using Convolutional Neural Networks in MRI Images," in IEEE Transactions on Medical Imaging, vol. 35, no. 5, pp. 1240-1251, May 2016.

[28] Havaei, Mohammad, et al. "Brain tumor segmentation with deep neural networks." Medical image analysis 35 (2017): 18-31.

[29] Milletari, Fausto, Nassir Navab, and Seyed-Ahmad Ahmadi. "V-net: Fully convolutional neural networks for volumetric medical image segmentation." 2016 Fourth International Conference on 3D Vision (3DV). IEEE, 2016.

[30] Bar, Yaniv, et al. "Chest pathology detection using deep learning with non-medical training." 2015 IEEE 12th International Symposium on Biomedical Imaging (ISBI). IEEE, 2015.

[31] Al Rahhal, Mohamad Mahmoud, et al. "Deep learning approach for active classification of electrocardiogram signals." Information Sciences 345 (2016): 340-354.

[32] Alipanahi, Babak, et al. "Predicting the sequence specificities of DNA-and RNA-binding proteins by deep learning." Nature biotechnology 33.8 (2015): 831.

[33] Roth, Holger R., et al. "Deeporgan: Multi-level deep convolutional networks for automated pancreas segmentation." International conference on medical image computing and computer-assisted intervention. Springer, Cham, 2015. 
[34] Chen, Hao, et al. "Standard plane localization in fetal ultrasound via domain transferred deep neural networks." IEEE journal of biomedical and health informatics 19.5 (2015): 1627-1636.

[35] Huynh, Benjamin Q., Hui Li, and Maryellen L. Giger. "Digital mammographic tumor classification using transfer learning from deep convolutional neural networks." Journal of Medical Imaging3.3 (2016): 034501.

[36] Ting, Daniel Shu Wei, et al. "Development and validation of a deep learning system for diabetic retinopathy and related eye diseases using retinal images from multiethnic populations with diabetes." Jama 318.22 (2017): 2211-2223.

[37] Fu, Huazhu, et al. "Retinal vessel segmentation via deep learning network and fully-connected conditional random fields." 2016 IEEE 13th international symposium on biomedical imaging (ISBI). IEEE, 2016.

[38] Poplin, Ryan, et al. "Prediction of cardiovascular risk factors from retinal fundus photographs via deep learning." Nature Biomedical Engineering 2.3 (2018): 158.

[39] Carneiro, Gustavo, Jacinto C. Nascimento, and António Freitas. "The segmentation of the left ventricle of the heart from ultrasound data using deep learning architectures and derivative-based search methods." IEEE Transactions on Image Processing21.3 (2012): 968-982.

[40] Yildirim, Ozal, Ru San Tan, and U. Rajendra Acharya. "An efficient compression of ECG signals using deep convolutional autoencoders." Cognitive Systems Research 52 (2018): 198-211.

[41] Shin, Hoo-Chang, et al. "Deep convolutional neural networks for computer-aided detection: CNN architectures, dataset characteristics and transfer learning." IEEE transactions on medical imaging 35.5 (2016): 1285-1298.

[42] Litjens, Geert, et al. "A survey on deep learning in medical image analysis." Medical image analysis 42 (2017): 60-88.

[43] Tajbakhsh, Nima, et al. "Convolutional neural networks for medical image analysis: Full training or fine tuning?." IEEE transactions on medical imaging 35.5 (2016): 1299-1312.

[44] Greenspan, Hayit, Bram Van Ginneken, and Ronald M. Summers. "Guest editorial deep learning in medical imaging: Overview and future promise of an exciting new technique." IEEE Transactions on Medical Imaging 35.5 (2016): 1153-1159.

[45] Shen, Dinggang, Guorong Wu, and Heung-Il Suk. "Deep learning in medical image analysis." Annual review of biomedical engineering 19 (2017): 221-248.

[46] Işın, Ali, Cem Direkoğlu, and Melike Şah. "Review of MRI-based brain tumor image segmentation using deep learning methods." Procedia Computer Science 102 (2016): 317-324.

[47] Mordang, Jan-Jurre, et al. "Automatic microcalcification detection in multi-vendor mammography using convolutional neural networks." International Workshop on Breast Imaging. Springer, Cham, 2016. 
[48] Dou, Qi, et al. "Multilevel contextual 3-D CNNs for false positive reduction in pulmonary nodule detection." IEEE Transactions on Biomedical Engineering 64.7 (2017): 1558-1567.

[49] Setio, Arnaud Arindra Adiyoso, et al. "Pulmonary nodule detection in CT images: false positive reduction using multi-view convolutional networks." IEEE transactions on medical imaging 35.5 (2016): 1160-1169.

[50] Ribli, Dezső, et al. "Detecting and classifying lesions in mammograms with deep learning." Scientific reports 8.1 (2018): 4165.

[51] Tajbakhsh, Nima, and Kenji Suzuki. "Comparing two classes of end-to-end machine-learning models in lung nodule detection and classification: MTANNs vs. CNNs." Pattern recognition 63 (2017): 476-486.

[52] Masood, Anum, et al. "Computer-assisted decision support system in pulmonary cancer detection and stage classification on CT images." Journal of biomedical informatics 79 (2018): 117128.

[53] Ma, Jinlian, et al. "Cascade convolutional neural networks for automatic detection of thyroid nodules in ultrasound images." Medical physics 44.5 (2017): 1678-1691.

[54] Näppi, Janne J., et al. "Deep transfer learning of virtual endoluminal views for the detection of polyps in CT colonography." Medical Imaging 2016: Computer-Aided Diagnosis. Vol. 9785. International Society for Optics and Photonics, 2016.

[55] Yan, Zhennan, et al. "Multi-instance deep learning: Discover discriminative local anatomies for bodypart recognition." IEEE transactions on medical imaging35.5 (2016): 1332-1343.

[56] Iqbal, Uzair, et al. "Deep Deterministic Learning for Pattern Recognition of Different Cardiac Diseases through the Internet of Medical Things." Journal of medical systems 42.12 (2018): 252.

[57] Zhang, Kailai, et al. "An effective teeth recognition method using label tree with cascade network structure." Computerized Medical Imaging and Graphics 68 (2018): 61-70.

[58] Chartrand, Gabriel, et al. "Deep learning: a primer for radiologists." Radiographics 37.7 (2017): 2113-2131.

[59] Chen, Hao, et al. "VoxResNet: Deep voxelwise residual networks for brain segmentation from 3D MR images." NeuroImage 170 (2018): 446-455

[60] Milletari, Fausto, et al. "Hough-CNN: deep learning for segmentation of deep brain regions in MRI and ultrasound." Computer Vision and Image Understanding 164 (2017): 92-102.

[61] Da, Cheng, Haixian Zhang, and Yongsheng Sang. "Brain CT image classification with deep neural networks." Proceedings of the 18th Asia Pacific Symposium on Intelligent and Evolutionary Systems, Volume 1. Springer, Cham, 2015 
[62] Korfiatis, Panagiotis, et al. "Residual deep convolutional neural network predicts MGMT methylation status." Journal of digital imaging 30.5 (2017): 622-628.

[63] Jnawali, Kamal, et al. "Deep 3D convolution neural network for CT brain hemorrhage classification." Medical Imaging 2018: Computer-Aided Diagnosis. Vol. 10575. International Society for Optics and Photonics, 2018

[64] Ngo, Tuan Anh, Zhi Lu, and Gustavo Carneiro. "Combining deep learning and level set for the automated segmentation of the left ventricle of the heart from cardiac cine magnetic resonance." Medical image analysis 35 (2017): 159-171.

[65] Romaguera, Liset Vázquez, et al. "Left ventricle segmentation in cardiac MRI images using fully convolutional neural networks." Medical Imaging 2017: Computer-Aided Diagnosis. Vol. 10134. International Society for Optics and Photonics, 2017.

[66] Chen, Mingqiang, et al. "Deep Learning Assessment of Myocardial Infarction From MR Image Sequences." IEEE Access 7 (2019): 5438-5446.

[67] Cheng, Jie-Zhi, et al. "Computer-aided diagnosis with deep learning architecture: applications to breast lesions in US images and pulmonary nodules in CT scans." Scientific reports 6 (2016): 24454.

[68] Setio, Arnaud Arindra Adiyoso, et al. "Validation, comparison, and combination of algorithms for automatic detection of pulmonary nodules in computed tomography images: the LUNA16 challenge." Medical image analysis 42 (2017): 1-13.

[69] Cicero, Mark, et al. "Training and validating a deep convolutional neural network for computer-aided detection and classification of abnormalities on frontal chest radiographs." Investigative radiology 52.5 (2017): 281-287.

[70] Chen, Sihong, et al. "Automatic scoring of multiple semantic attributes with multi-task feature leverage: A study on pulmonary nodules in CT images." IEEE transactions on medical imaging36.3 (2017): 802-814.

[71] Wang, Yu, et al. "Classification of mice hepatic granuloma microscopic images based on a deep convolutional neural network." Applied Soft Computing 74 (2019): 40-50.

[72] Frid-Adar, Maayan, et al. "GAN-based synthetic medical image augmentation for increased CNN performance in liver lesion classification." Neurocomputing 321 (2018): 321-331.

[73] Hossain, M. Shamim, et al. "Applying deep learning for epilepsy seizure detection and brain mapping visualization." ACM Transactions on Multimedia Computing, Communications, and Applications (TOMM) 15.1s (2019): 10.

[74] Farooq, Ammarah, et al. "A deep CNN based multi-class classification of Alzheimer's disease using MRI." 2017 IEEE International Conference on Imaging systems and techniques (IST). IEEE, 2017. 
[75] Yang, Hao, et al. "Multimodal MRI-based classification of migraine: using deep learning convolutional neural network." Biomedical engineering online 17.1 (2018): 138.

[76] Wu, Aaron, et al. "Deep vessel tracking: A generalized probabilistic approach via deep learning." 2016 IEEE 13th International Symposium on Biomedical Imaging (ISBI). IEEE, 2016.

[77] Huang, Xiaojie, Junjie Shan, and Vivek Vaidya. "Lung nodule detection in CT using 3D convolutional neural networks." 2017 IEEE 14th International Symposium on Biomedical Imaging (ISBI 2017). IEEE, 2017.

[78] Ribeiro, Eduardo, Andreas Uhl, and Michael Häfner. "Colonic polyp classification with convolutional neural networks." 2016 IEEE 29th International Symposium on Computer-Based Medical Systems (CBMS). IEEE, 2016.

[79] Huynh, Benjamin Q., Hui Li, and Maryellen L. Giger. "Digital mammographic tumor classification using transfer learning from deep convolutional neural networks." Journal of Medical Imaging 3.3 (2016): 034501.

[80] Bychkov, Dmitrii, et al. "Deep learning based tissue analysis predicts outcome in colorectal cancer." Scientific reports 8.1 (2018): 3395.

[81] Mordang, Jan-Jurre, et al. "Automatic microcalcification detection in multi-vendor mammography using convolutional neural networks." International Workshop on Breast Imaging. Springer, Cham, 2016. 